\title{
Agricultura intensiva y políticas de migración laboral: Jornaleros centroamericanos en México y marroquíes en Francia
}

\author{
MARTHA GARCÍA* \\ FRÉDÉRIC DÉCOSSE**
}

RESUMEN: En este trabajo se presentan dos ejemplos de política migratoria laboral a partir de la experiencia de jornaleros agrícolas centroamericanos en la frontera sur de México y de marroquíes en Francia. Se analizan los modelos de trabajadores huéspedes en el marco de una reflexión crítica sobre los actuales esquemas dominantes de "gestión» de la movilidad humana que obligan a los migrantes a «circular» permanentemente, y cuya condición burocrática fomenta la precariedad laboral y social. El estudio comparativo de dos permisos laborales internacionales parte del mercado de trabajo de la producción intensiva agroindustrial de la caña de azúcar en Chiapas (caso mexicano) y del jitomate en la región de las Bouches-du-Rhône (caso francés). Se revisan la Forma Migratoria de Trabajador Fronterizo (FMTF) y el contrato temporal Office des Migrations Internationales (OMI), para demostrar la lógica utilitarista y la tendencia represiva de las políticas migratorias en el funcionamiento de la división internacional del trabajo.

PALABRAS CLAVE: migraciones laborales, programas de trabajadores temporales, jornaleros centroamericanos y marroquíes, FMTF, OMI.

* Docente del Departamento de Sociedad y Cultura de El Colegio de la Frontera Sur, México.

** Doctor en Sociología por la Escuela de Altos Estudios en Ciencias Sociales, Francia. 
ABSTRACT: This paper presents two examples of migratory labor policy, based on the experiences of Central American agricultural laborers in the southern border of Mexico and of moroccans in France. It analyzes the models of guest workers in the framework of a critical analysis of the current main schemes of «managing» human mobility that require these migrants to permanently «circulate", and whose bureaucratic conditions lead to labor and social instability. We offer a comparative study of two international work permit contexts within the labor market of intensive agro-industrial production of sugar cane in Chiapas (mexican case) and of tomatoes in the Bouches-du-Rhône region (french case). This paper reviews the Migrant Frontier Worker Pass project (FMTF) and the Office of International Migrations (OMI) temporary contract scheme to demonstrate the utilitarian logic and repressive tendencies of migratory policies, revealing how the international division of labor functions. KEYWORDs: labor migration, temporary worker programs, central american and moroccan laborers, FMTF, OMI. 


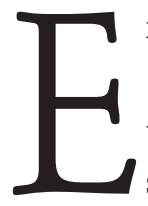
n 2005, la Comisión Mundial sobre las Migraciones Internacionales (cmmi) formuló una recomendación en torno a los programas de trabajadores huéspedes para que los Estados y el sector privado consideraran la opción de introducir programas de migraciones temporales cuidadosamente diseñados a fin de atender las necesidades económicas de los países de origen y destino (CMmi, 2005: 7). Sin embargo, esos programas de contratación temporal «en el origen» no son para nada un fenómeno nuevo, ya que aparecieron a principios del siglo xx y fueron implementados en distintas regiones del mundo, como Europa, Norteamérica y Asia (Castles, 1986; Izcara, 2012). Dentro de esas experiencias, tanto México como Francia tienen una amplia trayectoria.

A partir de 1917, México exporta mano de obra hacia Estados Unidos mediante el programa Bracero y, posteriormente, por medio de las visas $\mathrm{H} 2 \mathrm{~A}$ y H2B. De igual manera, existen flujos a Canadá vía el Programa de Trabajadores Agrícolas Temporales desde 1974. Durante la vigencia de estos dos esquemas, el número de trabajadores ha aumentado y, a excepción de Canadá, la presencia de inmigrantes irregulares ha sido una constante, con o sin permisos (Durand, 2006). Pero México no sólo exporta, sino que importa fuerza de trabajo desde Guatemala, históricamente de manera «irregular»y, desde 1994, legalmente mediante permisos laborales para trabajadores fronterizos (Castillo y Toussaint, 2010: 90). Desde 2008 está vigente la Forma Migratoria de Trabajador Fronterizo (FMTF).

En Francia, a partir del siglo XIX en el campo francés ya existían dispositivos parecidos para reclutar mano de obra agrícola migrante tanto temporal como permanente. Empero, desde 1960 se usan para contratar jornaleros originarios de las antiguas colonias francesas, Marruecos y Túnez, o sea, luego de la independencia de aquellos países, ya que al regresar de Francia los colonos quisieron seguir usando esa fuerza de trabajo en las nuevas fincas desarrolladas en el sur francés. El legado de esa tendencia son los permisos laborales temporales de la Office des Migrations Internationales, conocidos como contratos omi que existen desde 1946.

A un siglo de la implementación de esos esquemas, se ha desarrollado una literatura académica e institucional acerca del tema a partir del análisis 
de las condiciones administrativas, sociales, políticas y económicas en que se han aplicado los modelos de movilidad laboral temporal a nivel internacional. Tan sólo en México, los estudios han revelado las condiciones de vulnerabilidad a las que son expuestos los trabajadores huéspedes, y equiparan su condición a la de los jornaleros indocumentados (Durand, 2006; Izcara, 2010; Trigueros, 2008). En relación con las visas de trabajo, acusan la falta de protección gubernamental tanto en México como en Estados Unidos. En coincidencia con varios autores, investigaciones de organizaciones no gubernamentales registran prácticas viciadas en el proceso de reclutamiento, enganche, trámites, alojamiento y condiciones laborales, tal como lo reporta el Informe Jornaleros Safe (2012).

Estos diagnósticos pasan inadvertidos en las políticas mundiales que pretenden fincar el sistema de empleo temporal internacional con el paradigma de «trabajadores huéspedes». Las voces más alentadoras de esos programas provienen de autores ligados a la Organización Internacional del Trabajo (ОIт) y la Organización Internacional para las Migraciones (OIM), así como al Banco Mundial (BM) y la Organización Mundial del Comercio (OMC). Desde esas influyentes plataformas, los programas de trabajadores temporales son presentados a nivel internacional como una herramienta de gestión optimizada y compartida de los flujos migratorios, una estrategia win-win-win que beneficia tanto a los países de origen y destino como a los propios migrantes (Winters et al., 2003; Schiff, 2004; Amin y Matoo, 2005; Ruhs, 2006; Abella, 2006).

En ese contexto, la comparación de la FMFT y de los contratos OMI vigentes en México y Francia, respectivamente, se justifica al considerar la dinámica de integración económica regional en Europa y Norte-Centroamérica y las consecuentes políticas migratorias (Pellerin, 1999). En la construcción progresiva de la Unión Europea se ha establecido la libertad de circulación entre los países integrantes, lo que ha provocado el reemplazo de las migraciones tradicionales de jornaleros sureños (portugueses y españoles) por trabajadores originarios del norte de África. En Norteamérica, la integración económica vino acompañada de una política migratoria restrictiva,

$42 \frac{\text { SEGUNDO SEMESTRE } 2014}{\text { MIGRACIÓN Y DESARROLLO NÚM. } 23}$ 
con la construcción de muros en la frontera norte de México con Estados Unidos, y más selectiva de parte de Canadá con la imposición de visas.

Las implicaciones de esa integración y su mandato de control migratorio alcanzaron los límites del sur mexicano con Centroamérica. A inicios del siglo xxI las dinámicas migratorias y transfronterizas se complejizan al coexistir la movilidad tradicional con procesos emergentes como el desplazamiento de mexicanos de los estados fronterizos (incluso con $\mathrm{H} 2 \mathrm{~A}$ ) al vecino socio comercial del norte, algunos de forma autónoma y otros vinculados a los flujos centroamericanos. Con el bloque económico articulado por el Tratado de Libre Comercio de América del Norte (TLCAN), la demanda de mano de obra mexicana indocumentada se acentúa con una creciente incorporación de centroamericanos (Levine, 2004).

\section{JUEGO MIGRATORIO}

Dentro de esos grandes proyectos de integración económica regional se presenta un cambio de orientación en materia de política migratoria a nivel interno y extrabloques. Tales transformaciones no se reducen a la instauración de programas de contratación laboral temporal a partir de su periferia inmediata, ex o neocolonial (el Magreb en el caso europeo y México y Centroamérica en el caso del área norteamericana de libre comercio). Con esa tendencia se busca reforzar el control de las fronteras de la zona, lo cual se traduce a una tecnificación y una militarización de los dispositivos de vigilancia: Frontex en Europa y diversos planes de control fronterizo en los límites del norte de México desde la década de 1990 (Cornelius, 2001), hasta la política post-11/09, y el Plan Sur en la frontera de México con Guatemala y Belice (Nieto, 2006). Es decir, los horizontes comercial y de seguridad tienen como correlato la criminalización de los migrantes indocumentados (Palidda, 1999), por lo que las dimensiones represivas y utilitaristas de la política migratoria no se contradicen, ya que las fronteras, por más tecnificadas que sean, nunca son totalmente herméticas y producen de facto y de 
jure flujos de mano de obra «ilegalizada» (De Genova, 2004) y precaria que beneficia a la economía de los países receptores.

A partir de esa condición se puede sostener que las políticas migratorias represivas y sus paliativos burocráticos fomentan las migraciones indocumentadas empujando a los trabajadores a la precariedad y la segmentación de los mercados laborales en los niveles más bajos y, en particular, del sector menos protegido y demandante, el agrícola. Tanto la persistente y siempre renovada presencia de mano de obra «irregular», como los programas de contratación temporal, permiten mantener bajos los costos de producción de la alimentación humana (fruta, verdura, caña de azúcar). Esta variable aporta, al mismo tiempo, tanto a México como a Francia, cierto nivel de competencia frente a otras regiones de producción intensiva en el contexto de un mercado agrícola mundial marcado por la desregulación.

De ahí la relevancia de analizar las dinámicas migratorias que imponen los esquemas de trabajo temporal. Los esquemas referidos a la integración económica y política migratoria coercitiva y paliativa, se anuncian como estrategias en las cuales no hay perdedores o, más bien, todos los participantes tienen algo que ganar dentro de las configuraciones del «juego migratorio». Los países del Norte tienen acceso a la mano de obra requerida por sus mercados de trabajo secundarios, sin tener que aumentar los salarios y mejorar las condiciones de trabajo para volverlos atractivos para los trabajadores locales, mientras superan, según las palabras del experto de la CMMI: «la preocupación que despierta el posible asentamiento permanente de los inmigrantes temporales y la diversidad cultural que éstos fomentan dentro de la sociedad» (Ruhs, 2006: 8).

\section{Casos comparativos}

Desde el marco analítico de la expansión pragmática e ideológica de los programas de trabajadores internacionales temporales, se abordan de manera comparativa dos casos de producción agroindustrial en México y Francia.

$44 \frac{\text { SEGUNDO SEMESTRE } 2014}{\text { MIGRACIÓN Y DESARROLLO NÚM. } 23}$ 
Uno se ubica en el sur mexicano, donde se emprendió un proyecto de Estado para la siembra e industrialización de la caña de azúcar que demanda mano de obra del interior de México y de Guatemala. El otro ejemplo trata de la producción de hortalizas bajo invernadero en la región de las Bouches-duRhône al sur francés, donde se emplearon sucesivamente trabajadores de España, Portugal, Marruecos y Túnez. En esos escenarios regionales los jornaleros han consolidado rutas anuales al seguir el mismo proceso de producción de la caña de azúcar que requiere cuidados todo el año, siendo el periodo más intenso el de la cosecha (zafra); o en el extremo europeo el de varios ciclos de cultivos estacionales como las hortalizas de invernadero.

El caso mexicano se aborda a partir de los resultados de investigación sobre las condiciones de inserción laboral de los jornaleros agrícolas dedicados a la zafra en siete regiones cañeras del sur-sureste. Para este artículo resulta de especial interés sólo uno de los tres ingenios ubicados en los límites internacionales con Guatemala y Belice, donde se documentó la presencia de cortadores de caña internacionales para el periodo estudiado en la zafra 2011-2012. ${ }^{1}$ Se trata de la región cañera de Huixtla, en la zona del Soconusco, en Chiapas, en la cual se contratan trabajadores guatemaltecos. En este análisis se utilizaron técnicas antropológicas para el trabajo de campo, así como la realización de encuestas a trabajadores agrícolas locales y foráneos (migrantes nacionales e internacionales), productores, técnicos y planeadores de los ingenios, además del registro audiovisual. Para el caso francés los resultados son producto de una investigación de tesis doctoral sobre la migración bajo contrato omi de jornaleros marroquíes en la agricultura intensiva del sur de Francia. El trabajo de campo se desarrolló entre 2004 y 2009 en la región agrícola Bere-1’Étang, además de España y el norte de Marruecos. La metodología se basa en observaciones in situ, entrevistas semidirigidas a trabajadores, empleadores, sindicalistas, funcionarios y

${ }^{1}$ El proyecto se llamó «Jornaleros agrícolas de México y Centroamérica en los ingenios del sur-sureste: Retos para la política pública» (fondos sectoriales Sedesol-Conacyt). Los ingenios fueron La Joya (Campeche), Huixtla (Chiapas), Adolfo López Mateos (Oaxaca), San Rafael de Pucté (Quintana Roo), Azsuremex-Tenosique (Tabasco) y La Providencia y Tres Valles (Veracruz). Se estudiaron las zafras 2010-2011 y 2011-2012. 
médicos; trabajo de archivos y observación participante en un colectivo de defensa de los derechos de los jornaleros migrantes. ${ }^{2}$

\section{TRABAJADORES INTERNACIONALES EN LA FRONTERA SUR MEXICANA}

Desde hace por lo menos tres décadas, la frontera sur de México ha incorporado tanto a trabajadores nacionales como internacionales provenientes de Centroamérica en las tres agroindustrias instaladas en este límite. Estos enclaves azucareros fueron creados por el Estado mexicano para colonizar los límites mexicanos con sus vecinos de Belice y Guatemala y aprovechar el potencial agroecológico de estas regiones ya impulsado por fuerzas económicas basadas en la producción para la exportación de café en el Soconusco, Chiapas. La plataforma para la explotación de las nuevas tierras selváticas ${ }^{3}$ se consolidó a finales de los años setenta en estas regiones fronterizas con las primeras zafras, cosechas que requerían mano de obra abundante. Para tener una idea de esto, cabe precisar que tan sólo en una hectárea de caña promedio son imprescindibles 10 o 12 cortadores. Por otra parte, hay que tomar en cuenta que un ingenio podría alcanzar hasta 30 mil hectáreas en sus zonas de abasto. Esta actividad es de alto impacto en 227 municipios con 12 millones de personas (Sagarpa, 2007: 6).

Los trabajadores que respondieron al nuevo cultivo fueron de los estados del sur-sureste y trabajadores guatemaltecos y beliceños. Se puede imaginar la situación y el periplo de los jornaleros extranjeros cuando los caminos eran más inhóspitos y las distancias más largas; entonces, la experiencia más conocida era la de los flujos laborales de los guatemaltecos insertos en el corte de café en la región fronteriza del Soconusco. El cultivo de caña de azúcar demanda mano de obra a lo largo del año, siendo la zafra o cosecha el periodo

${ }^{2}$ Collectif de Défense des Travailleurs Agricoles Saisonniers (Codetras) fue creado en 2002 en Bouches-du-Rhône y está conformado por sindicatos de trabajadores y pequeños campesinos, asociaciones de solidaridad internacional y de defensa de los derechos de los migrantes.

${ }^{3}$ Para conocer parte de este proceso, consultar Fort (1979) y Camarena y Salazar (1991).

$46 \frac{\text { SEGUNDO SEMESTRE } 2014}{\text { MIGRACIÓN Y DESARROLLO NÚM. } 23}$ 
más importante entre noviembre y junio en todo el territorio nacional, calendario flexible según el volumen de caña que cada ingenio pueda moler. A diferencia del resto del periodo de producción de la caña, durante la zafra el ingenio no duerme, trabaja las 24 horas, lo que implica la contratación de miles de personas, trabajadores que se insertan a lo largo de la cadena productiva del azúcar: desde jornaleros que siembran, limpian y cortan la caña hasta los operadores de maquinaria en campo, ingenieros, obreros de fábrica, personal administrativo y, alrededor de ellos, un mundo de empleos indirectos relacionados con los servicios (alimentos, combustible, entre otros). De las enormes opciones laborales en este sector, el corte de caña es absorbido por hombres, la participación femenina es escasa y su contribución, en su mayoría, resulta ser un complemento al salario familiar. Empero, las mujeres cortadoras de tiempo completo son muy respetadas y tienen prestigio como «limpias, aguantadoras y fuertes».

La primera gran división en este mercado laboral se da entre cortadores locales (nativos o residentes de la región cañera) y cortadores foráneos (migrantes provenientes de fuera de la región cañera de una localidad, municipio, estado o de otro país). De hecho, en todo el territorio cañero nacional se insertan 60 mil cortadores, dentro de esos contingentes se movilizan jornaleros migrantes nacionales e internacionales, entre ellos están los que se distribuyen en las zonas cañeras de la frontera sur mexicana correspondientes a los ingenios de Huixtla, Chiapas; Azsuremex-Tenosique, Tabasco; y San Rafael de Pucté, Quintana Roo, que en promedio requieren de por lo menos 3 mil jornaleros: 966 mil 542 y 455, respectivamente. En el caso de Huixtla, la zafra 2011-2012 ocupó cerca de mil cortadores de caña, siendo 50 por ciento jornaleros agrícolas indígenas de Guatemala, ésta es la fuerza laboral foránea principal, el resto del ejército de cortadores son locales, muchos de las propias familias productoras. Los lugares de origen de los cortadores guatemaltecos son principalmente Sacatepéquez, Huehuetenango, Suchitéquez y Chimaltenango. Llegan en grupos familiares y de paisanaje, principalmente de habla mam y cakchiquel; se trata de trabajadores 
jóvenes entre 15 y 29 años que representan casi 70 por ciento de los empleados (García, 2013).

\section{Condición social y laboral}

La inserción laboral de esta población responde a esquemas flexibles donde su condición de vulnerabilidad se presenta en toda su expresión, no sólo en el ámbito exclusivo del trabajo (como contratación y salarios), sino en la situación prevaleciente del alojamiento (instalación en las galeras), rubro que debe ser considerado como parte de su estatus laboral en la medida que son trabajadores invitados a quienes los empleadores movilizan. La lista de los aspectos que contribuyen a esta condición de vulnerabilidad van desde la desregulación de los «contratos» de trabajo, eufemismo que se utiliza para el «enganche» - por usos y costumbres, un acuerdo de palabra entre las partes-, hasta la falta de control sobre el producto del trabajo de los cortadores al carecer de esquemas de contabilidad sobre su propia producción. Las prácticas alrededor del enganche son aceptadas por las partes dejando en desventaja a ambos, pero de particular repercusión en los cortadores, puesto que no existe documento alguno a partir del cual puedan exigir el cumplimiento de lo pactado en la negociación de la contratación.

En el modelo del trabajador agrícola, cortador de caña, cada engranaje de la relación laboral está fuera de toda regulación, supervisión o seguimiento; esta situación deriva en flagrantes violaciones a los derechos sociales, laborales y humanos, tanto de nacionales como de extranjeros, con las consecuencias obvias para los trabajadores internacionales que padecen abusos con el pretexto de su «ilegalidad». En la zafra que se reporta, 85 por ciento de los cortadores enganchados fue contratado de palabra, en tanto que 80 por ciento recibió dinero antes de su contratación cuyo monto ascendió entre 100 y 500 pesos. ${ }^{4}$ Los jornaleros contratados de palabra son suje-

${ }^{4}$ El rango se estimó en la pregunta de la encuesta aplicada. Sin embargo, en el trabajo de campo se constató que el pago de contratación fue de 200 pesos, la cuota más baja encontrada en los ingenios estudiados del proyecto. El monto del enganche varía según la región

$48 \frac{\text { SEGUNDO SEMESTRE } 2014}{\text { MIGRACIÓN Y DESARROLLO NÚM. } 23}$ 
tos de negociaciones donde el enganche funciona como el compromiso de cumplir con todo el periodo de zafra. Las jornadas laborales reportadas fueron entre seis y 12 horas, según la cuota establecida para el día y el tipo de terreno que se corte. El trabajo de la zafra exige no sólo destreza en el manejo del machete y demás instrumentos de labor, conocimiento de la planta (los trabajadores sienten la caña buena), sino además resistencia física para laborar a altas temperaturas bajo el sol. En ese caso, 64 por ciento de los cortadores deciden no descansar a lo largo de la zafra. Se puede suponer que ciertos jornaleros sí descansan, pero el porcentaje reportado como que «no descansa» significa que ese grupo podría sostenerse en esa tendencia a lo largo de los 168 días de cosecha programados.

Los trabajadores ganan por tonelada cortada de caña, la cual acumulan en los seis surcos (gavilla) donde cortan y amontonan la vara en "puños». Estos montones los levanta y deposita la máquina alzadora en el camión que transporta la materia prima al batey; un carro cañero suele tener una capacidad de 19 o 24 toneladas. Este proceso de recolección es ajeno al cortador puesto que, en la lógica del trabajo, él debe avanzar cortando caña y dejando a otros agentes el registro de su producción. Resultado: el cortador ignora el total de caña cortada al día ${ }^{5}$ y su pago semanal estará entre 500 y 999 pesos. En un extremo salarial está 19 por ciento con más de mil pesos y 1 por ciento con menos de 500 pesos.

Durante su estancia como trabajadores temporales en grupos o en familias los cortadores son alojados en instalaciones diversas, desde las galeras formales hasta amplios espacios al aire libre, protegidos por techos de lámina de dos aguas o en guardacoches y bodegones. La sola descripción de las condiciones de cada uno de estos inmuebles se llevaría bastante tinta. En resumen se documentó la precariedad de los asentamientos temporales donde los huéspedes «se encierran». Algunos de estos inmuebles se encuentran

cañera y las negociaciones del "contrato»; en zonas donde existen varios ingenios como Veracruz, el precio de la contratación llega a ser hasta de 6 mil pesos.

${ }^{5}$ El peso de la caña depende de varios factores: variedad de la caña, del "punto» de la vara (que esté sazón), del suelo (tipo de terreno: pedregoso, ralo), cañales enterrados (cañas tiradas, enraizadas), entre otros. 
dentro de las instalaciones de las organizaciones de productores; los gastos de agua y luz en las galeras corren a cargo de los contratistas de los jornaleros pertenecientes a las filiales campesinas y rurales del Partido Revolucionario Institucional (PRI). ${ }^{6}$ Se carece de normatividad en torno a las condiciones arquitectónicas ${ }^{7}$ y servicios mínimos, por lo que los riesgos de salud son latentes. Resulta importante señalar estos aspectos en la medida en que el alojamiento de los trabajadores invitados, huéspedes temporales, requieren de condiciones mínimas para poder trabajar, aspectos que no son tomados en cuenta en los requisitos para el ingreso de trabajadores internacionales temporales. Situación que sin duda vulnera los derechos de los jornaleros y sus familias. Tras la jornada de trabajo, el lugar de descanso demanda labores extras para que la cotidianidad funcione: llevar y cortar leña, colocar lonas para la lluvia, acarrear agua para bañarse y cocinar, limpiar lodazales... El espacio de producción se articula con el de la reproducción social en el que el trabajador y su familia invierten horas de trabajo con el fin de lograr estar en condiciones de presentarse a laborar diariamente.

\section{Permiso de trabajador fronterizo}

En Chiapas, los guatemaltecos que llegan al corte de caña en la región del ingenio de Huixtla parecen muy familiarizados con los trámites migratorios, de cualquier manera la falta de escolaridad y el hecho de que para los jornaleros mayas su lengua materna no sea el español —idioma generalizado en México-y la relación subordinada frente a empleadores, son elementos que los colocan en desventaja en función de su desconocimiento y desinformación para acceder a recursos de atención social. ${ }^{8}$ La Forma Migratoria de

${ }^{6}$ Unión Nacional de Productores de Caña de Azúcar de la Central Nacional Campesina (CNC) y Unión Nacional de Cañeros, A.C., de la Confederación Nacional de Propietarios Rurales (CNPR).

7 Esto ocurre en todos los ingenios estudiados; prevalece una falta de normas de construcción en términos funcionales, adecuadas para los trabajadores y sus familias: materiales adecuados o ergonomía, entre otros (Palacio, 2012).

${ }^{8}$ El Programa de Atención a Jornaleros Agrícolas considera entre los trámites para los recursos la «forma migratoria», según las Reglas de Operación, 2013. En consultas con mandos

$50 \frac{\text { SEGUNDO SEMESTRE } 2014}{\text { MIGRACIÓN Y DESARROLLO NÚM. } 23}$ 
Trabajadores Fronterizos (FMTF) surge del Programa de Migración para la Frontera Sur de México, que contempló cuatro líneas estratégicas para una mejor gestión en esta parte del país: a) facilitación de la documentación de los flujos migratorios; $b$ ) mayor protección de los derechos de los migrantes; c) mayor seguridad fronteriza; $y$ d) una mayor y mejor infraestructura material y tecnológica. Entre los objetivos se planteó convertir esta franja en una zona digna, ordenada, segura y moderna para facilitar la vida transfronteriza y la gestión de los flujos migratorios (INM, 2012).

El programa está vigente desde 2008, aunque se planteó con una duración de cuatro años; ${ }^{9}$ su diseño respondió a la necesidad de facilitar la internación de trabajadores de Guatemala y Belice con intenciones de emplearse en los sectores agrícolas, industriales y de servicios en los estados de Campeche, Chiapas, Tabasco o Quintana Roo. Antes de este programa, los permisos laborales sólo se extendían a guatemaltecos empleados en la agricultura chiapaneca. ${ }^{10} \mathrm{El}$ permiso se tramita en las oficinas del Instituto Nacional de Migración (INM), entidad que asegura en su portal electrónico que el procedimiento es "rápido y sencillo», igualmente permite el ingreso de dependientes económicos; la vigencia es de un año. ${ }^{11}$

Los trabajadores agrícolas centroamericanos, en su mayoría guatemaltecos, que ingresan a territorio mexicano con permisos laborales, han cambiado su cantidad. A principios de siglo pasaron de $69 \mathrm{mil} \mathrm{a} 46 \mathrm{mil}$ entre 2000 y 2003, dato que corresponde a los jornaleros agrícolas empleados en Chiapas. En tanto, casi una década más tarde, en el periodo 2010-2011, en plena vigencia de la implementación de la FMTF, la cifra de los trabajadores internacionales llegó a 26 mil 774 para Chiapas, 52 para Tabasco y uno para Quintana Roo. Para 2011, las cifras fueron 29 mil 73 para Chiapas, 29

medios en las oficinas de Sedesol, se justificaba esta omisión en virtud de que «los extranjeros no tienen derecho a este programa».

9 Con las reformas introducidas por la Ley de Migración y el cambio de gobierno (20122018), aún se desconoce cuál será la viabilidad de este programa.

${ }^{10} \mathrm{El}$ antecedente inmediato es la Forma Migratoria para Visitantes Agrícolas Guatemaltecos (FMVA), un breve repaso por la situación administrativa de estos trabajadores se encuentra en Ángeles y Rojas (2000).

${ }^{11}$ Los requisitos pueden consultarse en: www.inm.gob.mx. 
para Tabasco y cinco trabajadores para Quintana Roo. ${ }^{12}$ En Huixtla, 70 por ciento de los jornaleros extranjeros obtuvo su permiso laboral, y de éstos menos de la mitad lo tramitó personalmente. Otro 20 por ciento señaló que fue el cabo (líder de las cuadrillas de trabajadores y enganchador), quien lo apoyó en su trámite. Un porcentaje significativo (37 por ciento) desconoció quién hizo su trámite en las oficinas del INM. Los permisos son portados por sus usuarios debido a que «los buscan para los papeles». ${ }^{13}$

Sobre las condiciones en que son trasladados los trabajadores, los empleadores se quejan de la tardanza en el trámite dada la multitud de jornaleros y familias, pues deben pagar alimentación a veces hasta por dos días en el trayecto, lo que resulta oneroso para los contratistas, según afirman. En tanto, los cortadores se lamentan de las malas condiciones de transportación por la espera del papeleo: dormir al aire libre, falta de alimentos, entre otros.

\section{JORNALEROS MIGRANTES}

EN LA AGRICULTURA INTENSIVA FRANCESA

En la región de las Bouches-du-Rhône, en el sur de Francia, la producción de hortalizas bajo invernadero surgió en la década de 1960 y se concretó al norte del lago de Berre. Muchos de los productores provienen del barrio marsellés de Mazargues, de donde fueron expulsados durante el decenio anterior bajo la presión urbanística de la metrópoli. En su mayoría se trata de descendientes de migrantes italianos que se dedicaron al trabajo de la tierra en el cinturón hortícola de la ciudad foceana. La colonización agrícola de las orillas del lago de Berre se hizo a través de frentes pioneros, una lógica de apropiación de espacio y de la naturaleza común a varias experiencias de agricultura intensiva alrededor del mundo. La reubicación de esas

\footnotetext{
${ }^{12}$ Las estadísticas están disponibles en el portal electrónico del INM.

${ }^{13}$ El Informe Jornaleros Safe (2012), reporta que la retención de los documentos migratorios de parte del enganchador o patrón es un recurso para mantener cautivo al empleado o sujetarlo bajo amenaza.
}

$52 \frac{\text { SEGUNDO SEMESTRE } 2014}{\text { MIGRACIÓN Y DESARROLLO NÚM. } 23}$ 
empresas expulsadas ocurre en la época de «modernización» de la agricultura francesa caracterizada por la introducción de nuevas técnicas e infraestructura (como el invernadero) y la intensificación de los cultivos, entre otros. Cincuenta años después, aquella producción agrícola sigue siendo regida por una lógica intensiva, es decir, una utilización máxima de todos los factores productivos (materias primas, capital y trabajo) con el fin de aumentar las cantidades recolectadas por hectárea.

Ejemplo de lo anterior es el cultivo del jitomate. Bajo invernadero, las matas de jitomate son sembradas en bultos de sustrato neutro a donde les llega agua y fertilizantes por medio de un goteo. Dado su grado de tecnificación, el cultivo requiere una inversión por hectárea que varía entre 500 mil pesos por un invernadero de plástico y 12 millones de pesos cuando se trata de una estructura de vidrio. Tal nivel de inversión genera una «acumulación forzada» (Mollard, 1977), así como una subsunción (por lo menos formal) del trabajo al capital. Dicha tendencia está reforzada por el valor del capital técnico involucrado en el manejo del cultivo. Aparte del sistema de riego por goteo señalado, cabe precisar que el control de la temperatura, de la higrometría y de los aportes de agua y fertilizantes está automatizada, es decir, se monitorea por computadora. En los invernaderos más tecnificados, las hileras de jitomates de crecimiento indefinido están separadas por rieles sobre los cuales los trabajadores se desplazan, montados sobre carriolas que no sólo les permiten circular, sino subir y bajar, según la altura en que se lleven a cabo las distintas tareas que deben realizar. Si bien este sistema reemplaza el uso de zancos que provoca accidentes por caída, garantiza al mismo tiempo un aumento del rendimiento del jornalero que en temporada de cosecha (es decir, de febrero a octubre) puede recolectar a diario entre 300 y 750 kilos de jitomate. ${ }^{14}$

El trabajo ha sido frecuentemente considerado como el elemento clave del funcionamiento de la agricultura intensiva, después del estudio pionero de Fisher sobre los cultivos de California (1951). Si bien la remuneración de la

${ }^{14}$ Entrevista con M. Fezaï, jornalero magrebí de 53 años, empleado en un invernadero del llano de Berre-l'Étang. Le «Gourbi» (Berre-l'Étang, Bouches-du-Rhône, Francia), julio de 2005. 
fuerza de trabajo representa más de la mitad de los costos de producción de las empresas consideradas, y aunque la disponibilidad de la mano de obra sea una preocupación central para los patrones, no se puede analizar la producción bajo invernadero sólo como un sistema productivo intensivo en trabajo. En primer lugar porque, como se detalló anteriormente, dicha producción exige un grado elevado de capital constante. En segundo lugar, porque la artificialización del medio permite una mejor distribución de la demanda del trabajo. En efecto, si en un campo de cultivo el factor climático es una amenaza directa para la cosecha (una elevación brutal de la temperatura puede, por ejemplo, acelerar la maduración de la hortaliza), el techo y el sistema de ventilación/calefacción de un invernadero tecnificado libera al productor de la obligación de cosechar todo con prisa. Sin embargo, la movilización de la mano de obra en los invernaderos del sur de Francia responde a una lógica de uso intensivo porque el capital variable es el único factor sobre el cual el empresario tiene control (la sujeción establecida entre él y los bancos, los proveedores de insumos y distribuidores, le quita toda posibilidad de reducir la cantidad de capital constante invertida).

Si bien durante mucho tiempo esa agricultura fue familiar — basada en la auto-explotación del trabajador y su familia (Chayanov, 1985)—, hoy tiene más bien una estructura esencialmente asalariada. No obstante la alta tecnificación, tradicionalmente en Francia el derecho social —es decir, el derecho laboral y el derecho de la protección social - ha sido menos protector en el sector agrícola que en otros sectores de la economía. Esto provocó desde mediados del siglo xx la huida progresiva de los trabajadores nacionales y la consecuente necesidad de importar mano de obra migrante. Esta experiencia corresponde a lo analizado por Berlan en el caso californiano: «A partir del momento que una región (o una finca) se especializa en uno o varios cultivos intensivos tiene que disponer de los recursos de mano de obra necesarios: requiere entonces que exista un mecanismo social seguro que garantice que los productores tendrán acceso a los trabajadores requeridos» (1986: 15). ${ }^{15}$ En promedio, las fincas hortícolas emplean el equivalente a

${ }^{15}$ Traducción de los autores.

$\mathbf{5 4} \frac{\text { SEGUNDO SEMESTRE } 2014}{\text { MIGRACIÓN Y DESARROLLO NÚM. } 23}$ 
siete personas de tiempo completo al año por hectárea, un dato que no revela el hecho de que la mayoría de la fuerza de trabajo es «temporal». Se puede representar el sistema de mano de obra por círculos concéntricos, teniendo como centro al empresario que generalmente ya no tiene ayudantes familiares.

El primer círculo lo componen trabajadores «especializados», o sea, los capataces o jefes de cuadrilla en temporada de cosecha. Su categoría laboral y migratoria es estable. Participan en todo el ciclo del cultivo: preparación del invernadero, siembra, mantenimiento del cultivo, cosecha y quitar las matas al finalizar el ciclo. Se trata de inmigrantes establecidos desde cierto tiempo en la región de producción, cuyo origen nacional ilustra la superposición de las olas sucesivas de migración que el Estado y los productores fueron organizando año tras año. Esos trabajadores son originarios de España, Portugal, Marruecos o Túnez; entraron en Francia como «turistas» o con el contrato de trabajo temporal omi. Pasado el tiempo y a través de luchas colectivas y amnistías, consiguieron un permiso de residencia y trabajo permanente, incluso viven con sus familias en suelo francés.

El segundo círculo lo conforman los trabajadores temporales bajo contrato OMI, empleados por una temporada de cuatro a seis meses; son reclutados en Marruecos o Túnez por la gente del círculo precedente a partir de los vínculos familiares o comunitarios que les unen. A diferencia de los trabajadores estables, los jornaleros omi son directamente alojados en la finca, lo que permite al patrón cobrar una renta por el uso de viviendas precarias, además de otros servicios (luz) o mercancías (pan) que se descuentan del sueldo. Otra ventaja para el empresario es que esos empleados están siempre bajo su control y disponibles para trabajar como, por ejemplo, cuando se trata de cargar mercancía de noche para entregar un pedido urgente. No obstante, se dedican principalmente a la cosecha del jitomate como al mantenimiento de las matas (de crecimiento indefinido aprovechando toda la altura del invernadero y así aumentar el rendimiento por hectárea). Deben entonces amarrarlas y enredarlas a un hilo colgado al techo, empacarlas hacia abajo, quitar las hojas supernumerarias para acelerar la maduración de los jitomates. En algunas empresas, les toca también aplicar los plaguicidas. 
La cosecha es una tarea pesada porque casi siempre los jitomates maduros se encuentran abajo, lo que obliga al jornalero a laborar agachado o de rodillas.

El tercer círculo agrupa a los trabajadores eventuales, es decir, los jornaleros ocupados unas cuantas semanas durante la temporada alta de la cosecha. La composición de este grupo es variable según la empresa: puede ser mano de obra indocumentada o proporcionada por empresas de inserción social (mediante el subsidio del Estado) o de trabajo temporal. Si bien históricamente se reclutaba a la población local (principalmente mujeres e hijos de migrantes), desde hace unos años se moviliza fuerza de trabajo latinoamericana (en su mayoría de Ecuador) empleada por empresas de trabajo temporal españolas, una forma de contratación flexible cuyo éxito, en el marco de la agricultura intensiva, se explica al combinar subcontratación y precariedad laboral, y la consecuente dificultad para aplicar los derechos laborales y sociales de los trabajadores. En cuanto al alojamiento, en la región Berre-l'Étang media centena de jornaleros magrebíes indocumentados se hospedaba en un lugar (hoy desalojado) denominado "Gourbi». Este antiguo terreno de cultivo sin luz ni agua corriente, donde se aglomeraban viejas caravanas y chabolas hechas con el plástico de los invernaderos que lo rodeaban, servía entonces de vivero de fuerza de trabajo «ilegalizada» donde los productores acostumbraban surtirse para contemplar su cuadrilla.

\section{Sistema OMI}

Enmarcado por acuerdos bilaterales entre el país receptor y los Estados expulsores, el sistema OMI es un dispositivo de contratación de trabajadores agrícolas «en el origen», con autorización para emplearse en la agricultura francesa por un periodo máximo de seis meses. Después, los jornaleros ya no tienen derecho a permanecer en Francia y deben regresar a su país como condición para poder volver el año siguiente. En el marco de este programa de migraciones temporales (PMT), el trabajo por contrato vale como permiso de residencia, lo cual es la marca del «utilitarismo migratorio» (Morice, 2001), 
o sea de la propensión que tienen el Estado y los patrones de reducir y organizar el fenómeno migratorio únicamente en función de la utilidad económica para el país receptor. Los trabajadores importados a través de este mecanismo son hombres originarios de territorios rurales y marginados del norte de Marruecos (región del Rif y sus alrededores) y de Túnez (comarca de Jendouba); la edad promedio está entre 20 y 50 años, y el buen estado de salud queda certificado por un examen médico.

De acuerdo con la ley, el derecho de contratar jornaleros omi sólo se otorga a los productores que no encontraron previamente mano de obra local (requisito establecido en prácticamente todos los esquemas de contratación foránea). Esta condición de "protección del mercado nacional del trabajo» casi no se aplica en los hechos. Es necesario precisar que los productores organizados establecen una relación de fuerza con el Estado que les garantiza un acceso amplio a la fuerza de trabajo omi. A un nivel más macro, se puede analizar esto como la contraparte por el hecho de que, a diferencia de otras producciones agrícolas (como la cerealicultura), el cultivo de hortalizas recibe poco subsidio público, lo que significa que dichas empresas están más expuestas que la competencia internacional. Ahora bien, la posibilidad del productor de contratar un jornalero a través de este programa representa una garantía de mantener bajo el costo del trabajo, ya que la situación de cautividad del jornalero omi permite una extracción máxima de la plusvalía de su trabajo.

El sistema de reclutamiento omi es nominal. Si bien el mecanismo de contratación de un jornalero está formalmente controlado por el Estado, le precede necesariamente la relación entre el trabajador y el patrón, o por lo menos entre el obrero y el capataz, a quien el productor delega la responsabilidad de completar los grupos de trabajo. Más allá del formalismo administrativo, existe un acuerdo previo que muchas veces se acompaña de un acto de compra-venta, que representa el cerrojo de acceso al «mercado negro de los derechos a emigrar y trabajar en Francia» (Berlan, 1991: 56). ${ }^{16}$ Los contratos se compran hasta por 6 mil euros (entre cien mil pesos mexicanos),

${ }^{16}$ Traducción de los autores. 
cantidad que el futuro jornalero puede conseguir al contraer una deuda con el patrón. Tal cantidad genera una dependencia del jornalero al empleo, entonces el patrón, quien tiene la libertad de renovar o no el contrato el siguiente año, crea un «compromiso» que no es sólo económico, sino también moral, porque el jornalero ve su contratación como un favor que le hace el productor, «favor» por el que la contraparte exige lealtad.

\section{Vulnerabilidad del jornalero}

El agro siempre ha sido en Francia un sector económico caracterizado por salarios y derechos laborales en desventaja frente al resto de la economía. Históricamente, la movilización de la fuerza de trabajo migrante de los campesinos del Sur permitió mantener sueldos bajos a favor del diferencial salarial entre países expulsores y receptores; de tal manera que los productores consideran el salario mínimo como un salario máximo, es decir, como la remuneración mensual de la fuerza de trabajo que no puede ser rebasada aunque el jornalero trabaje 300 horas al mes. Empleado durante 23 años en la misma empresa como jornalero bajo contrato omi, el señor Aït Baloua, un trabajador marroquí de 55 años, explica:

No sabía yo nada del salario mínimo. Después hablé con otros y entonces me di cuenta que me engañaban [...] Cuando el salario mínimo estaba a 40 [francos], nosotros cobramos 30. Cuando llegó el euro en 1999, estaba a 7 euros la hora, y a nosotros nos pagaban 4.68. Cobramos 5 a partir de 2005 (Décosse, 2011: 279-280).

El día que el patrón de este trabajador vendió la empresa sin avisar y que dejó de renovar su contrato, este jornalero decidió demandarlo, ya que se sentía liberado de cualquier obligación de lealtad hacia él. Gracias a una libreta donde anotaba escrupulosamente sus horarios reales de trabajo, se estableció que durante todos estos años su empleador no le había pagado 6 mil 300 horas extras, o sea, el equivalente de 3 años de trabajo, según argu-

$58 \frac{\text { SEGUNDO SEMESTRE } 2014}{\text { MIGRACIÓN Y DESARROLLO NÚM. } 23}$ 
mentó el Colectivo de Sindicatos y Asociaciones Involucrados en la Defensa de los Derechos de los Jornaleros Migrantes en las Bouches-du-Rhône (Codetras, por sus siglas en francés), que apoyó la queja del señor Aït Baloua. El empleador pagó una tarifa inferior al salario mínimo, no pagó las horas extras ni aquellas a la tarifa normal, no respetó el descanso ni el horario semanal laboral. Este tipo de abusos son frecuentes en el mundo del jornalero omi. A lo anterior se agrega también el préstamo de mano de obra (cuando un patrón presta sus jornaleros a otro productor), el cobro de la renta a una tarifa superior a la que define el convenio (por el uso de viviendas muchas veces insalubres), la manipulación de plaguicidas sin capacitación ni protección, la escasa declaración de los accidentes laborales... En pocas palabras, el derecho laboral de estos trabajadores está puesto entre paréntesis a causa de su precariedad estatutaria y de su dependencia hacia el patrón.

\section{TRABAJADORES INTERNACIONALES Y PRECARIEDAD MIGRATORIA}

Los dos casos presentados confirman la premisa de la política migratoria que evalúa y difunde estos modelos de trabajo internacional temporal con el fin de gestionar las migraciones circulares. Las condiciones en que estos esquemas funcionan, remitiéndose al ámbito exclusivamente administrativo, derivan en flagrantes violaciones a los derechos de los jornaleros agrícolas contribuyendo así a su vulnerabilidad social y laboral. En cuanto a las premisas de la política económica, estos trabajadores internacionales, que van del Magreb a Francia y de Centroamérica a México, son requeridos por las economías regionales en la medida en que su participación ha sido histórica y estructuralmente necesaria y explotada, cuya plusvalía se advierte por las condiciones de precariedad de los mercados de trabajo.

En México esa precariedad representa dos caras de la misma moneda de la política migratoria dentro de un mercado laboral acotado, debido a que históricamente se ha contado simultáneamente con un flujo «irregular» de trabajadores (sin documentos) y otro flujo «regular» (con documentos). Este juego migratorio vulnera a un grupo de trabajadores y a otro lo asegura 
garantizando un empleo efectivo y cautivo en la agricultura, aun cuando padezcan la desregulación laboral. En los campos de cultivo, la fuerza de trabajo indocumentada es un complemento ideal al empleo de jornaleros bajo FMTF. En Francia también se registra la presencia de mano de obra «indocumentada", pues los trabajadores migrantes están principalmente bajo el estatuto de omI. Si sobre el papel la contratación «en origen» manejada por el Estado garantiza al trabajador el acceso a sus derechos laborales, el hecho de que el permiso de residencia sea corto (seis meses) y que su renovación dependa del empleador, mantiene al trabajador en una situación administrativa inestable, la cual le impide exigir el cumplimiento de la ley laboral.

Hay que destacar que, siendo ambos programas de migración temporal, los dispositivos OMI y FMTF son muy distintos en su esencia y su funcionamiento. A nivel político, el contrato omi nace de un acuerdo bilateral entre países (expulsor y receptor), en tanto que la FMTF es un mecanismo unilateral, lo cual excluye a Guatemala y Belice de la orientación del programa en términos de cuotas, garantías laborales y sociales a favor de sus connacionales, quedando en manos de los empresarios el proceso de contratación y todo lo que implica el trayecto e instalación de los trabajadores y sus familias. Asimismo, este recurso es omiso a la presencia tradicional de trabajadores hondureños y salvadoreños excluidos de este programa (argumentar que no son fronterizos revela una ceguera institucional). En el caso francés, la importación de fuerza de trabajo responde directamente a una necesidad laboral definida por el sector patronal y la Secretaría del Trabajo, y está limitada en el tiempo.

\section{Reclutamiento LABORAL}

Si bien tanto en el caso francés como en el mexicano la política migratoria es un elemento clave para entender la situación de la mano de obra foránea, no da elementos para comprender cómo funciona realmente el sistema laboral internacional: ni de los cortadores de caña centroamericanos en la

$60 \frac{\text { SEGUNDO SEMESTRE } 2014}{\text { MIGRACIÓN Y DESARROLLO NÚM. } 23}$ 
agroindustria mexicana ni de los cosechadores de hortalizas magrebíes en la agroindustria francesa. Los contratos OMI y FMTF no son controlados sólo por la administración gubernamental, de hecho los contratistas juegan un papel clave en la intermediación entre el trabajador y el patrón. A pesar de eso, el esquema es distinto: mientras los marroquíes son reclutados directamente en su pueblo por intermediarios que trabajan como capataces en los campos y con quienes pueden llegar a tener hasta relaciones de parentesco, los guatemaltecos son enganchados por el cabo que los apoya en sus trámites migratorios, llevándolos a las galeras o a sus centros de alojamiento y supervisándolos a su llegada en la frontera mexicana.

Las cuadrillas son más estables en Francia, dado el hecho de que los contratos omi son nominales y se renuevan año tras año. En el sur de México la fMTF se tramita de manera personal o en grupos. Para el caso de los cortadores de caña, éstos vienen conformados desde el lugar de origen, incluso con familia, aun cuando no se renuevan, las localidades participantes en las zafras suelen ser las mismas. La intermediación está sujeta a lealtades recíprocas en función de los mínimos de atención en el proceso de contratación: garantizar el transporte y comidas básicos en el trayecto de sus pueblos de origen a la frontera sur (ni pensar en el alojamiento de los jornaleros). Tales relaciones en el nivel de parentesco y comunitario generan una obligación de lealtad del trabajador hacia el intermediario, misma que se extiende al patrón, «quien ve» por ellos. De esta manera, se fincan prácticas paternalistas inscritas en actitudes de protección y castigo a los dependientes, dispositivos que son parte del esquema de gestión de la mano de obra (Morice, 1999).

En los casos tratados, la deuda o el enganche crea la dependencia. Tal compromiso funciona como el mecanismo para la inserción laboral, es decir, permite el acceso al trabajo y retiene al trabajador limitando su movilidad. En Francia corresponde al equivalente de una temporada de trabajo de medio año y en México a la temporada de cultivo de la caña menor a cinco meses. Al profundizar en la comparación de los sistemas de reclutamiento, cabe señalar que en la experiencia mexicana, el acuerdo de palabra es la base de 
la relación laboral —el trámite migratorio no obliga a regulación laboral alguna-; en Francia se trata de contratos escritos y estándares (lo que significa que son comunes a todos los jornaleros migrantes y que los derechos otorgados no varían en cada campo de trabajo).

Resulta interesante precisar que los pactos orales eran también la única forma de cerrar un contrato en el agro francés hasta finales del siglo XIX y, justamente, fue la contratación de obreros migrantes lo que permitió la introducción del acuerdo escrito en el sector agrícola cuando ya era de uso común en el mundo industrial. En México, el acuerdo de palabra forma parte de los usos y costumbres en el medio rural, donde la palabra es un valor dentro del régimen de «arreglos de respeto», se da entre el patrón y la cuadrilla representada por el contratista o el cabo, de modo que los derechos otorgados dependen de la correlación de fuerza que existe entre estos dos actores y, según la historia de explotación y discriminación mexicana, los jornaleros están en franca desventaja como lo sugiere el pago de enganche más barato a nivel nacional en la agroindustria azucarera.

Si bien es cierto que el acuerdo de palabra no ofrece garantías, en el sentido de que el contenido del trato no está plasmado en un documento al que el jornalero puede recurrir, el caso francés muestra que un contrato escrito puede coexistir con cierto grado de inefectividad del derecho. Los trabajadores internacionales FMTF están en desamparo total en términos de su inserción laboral no regulada tanto en sus condiciones de trabajo como de alojamiento. Los jornaleros OMI, con tal de seguir siendo contratados cada año, tienen que aceptar que sus derechos laborales sean puestos entre paréntesis: aceptan un pago inferior al salario mínimo y condiciones de alojamiento insalubres. Al final, lo que determina que se cumplan o no los derechos, no es tanto su carácter oral o escrito, ni tan poco quién ha negociado, sino el grado de cautividad que se ejerce sobre su persona y su fuerza de trabajo.

Como se puede advertir en la presentación de estos dos casos de reclutamiento de mano de obra internacional en el sur de México y Francia a través de permisos laborales temporales, el estatus migratorio precario justifica un modelo de explotación del trabajador migrante originario de la periferia

$62 \frac{\text { SEGUNDO SEMESTRE } 2014}{\text { MIGRACIÓN Y DESARROLLO NÚM. } 23}$ 
inmediata a favor de la rentabilidad de las economías integradas. La falta de regulación laboral es un factor disonante en cuanto a la tendencia de considerar los derechos de los migrantes. La disociación entre los derechos del mercado y los derechos al trabajo marcan una tensión en las políticas migratorias que sólo abonan a la precariedad y marginación laboral a favor del capital. Las experiencias mundiales de los «trabajadores huéspedes» han demostrado que el aporte social y humano a las economías mundiales no han favorecido en nada al diseño de nuevos esquemas de contratación internacional. Los «condenados de la tierra» (Fanon, 1963) del siglo XXI están en ese margen.

\section{Bibliografía}

Abella, Manolo (2006), «Policies and Best Practices for Management of Temporary Migration», International Symposium on International Migration and Development, United Nations Secretariat, Turín, Italia, 28-30 de junio.

Amin, Mohammad y Aaditya Matoo (2005), «Does Temporary Migration have to be Permanent», World Bank Policy Research Working Paper, núm. 3582, Washington D.C., World Bank.

Ángeles, Hugo y Martha Rojas (2000), «Migración femenina internacional en la frontera sur de México», Papeles de Población, México, núm. 23, pp. 127-151. Berlan, Jean-Pierre (1986), «Agriculture et Migrations», Revue Européene de Migrations Internationales, Poiters, vol. 2, núm. 3, pp. 9-32.

et al. (1991), L'integration des Immgrés en Milieu Rural, París, INRA/CEDerS/ Université Aix Marseille II.

Camarena, Luis y Sergio Salazar (1991), Estudios ecológicos preliminares de la zona sur de Quintana Roo, Chetumal, ciaroo.

CAstles, Stephen (1986), "Guest-Worker in Western Europe, an Obituary», International Migration Review, vol. 20, núm. 4, pp. 761-778.

CAstillo, Manuel Ángel y Mónica Toussaint (2010), «Migraciones centroamericanas en el estado de Chiapas y sus impactos socioculturales», Migrantes: mirando al sur. Entrecruzamientos culturales en las migraciones contemporáneas, México, Agencia Española de Cooperación Internacional, Centro Cultural de España en México-Instituto Nacional de Migración, pp. 88-97. 
ChayAnov, Alexander V. (1985), La organización de la unidad económica campesina, Buenos Aires, Nueva Visión.

Cornelius, Wayne (2001), «Death at the Border: Efficacy and Unintended Consequences of U.S. Immigration Control Policy, 1993-2000», Cuadernos de Trabajo, Center for Comparative Immigration Studies-UCSD, vol. 27, núm. 4, diciembre. CMmI (2005), Las migraciones en un mundo interdependiente: nuevas orientaciones para actuar, Ginebra.

Décosse, Frédéric (2011), Migrations sous Contrôle. Agriculture Intensive et Saisonniers Maroconais sous Contrat OMI, París, eHEsS.

De Genova, Nicholas (2004), "The Legal Production of Mexican/Migrant "Illegality"», Latinos Studies, vol. 2, pp. 160-185.

Durand, Jorge (2006), Programas de Trabajadores Temporales. Evaluación, análisis del caso mexicano, México, Segob-Conapo.

Fanon, Frantz (1963), Los condenados de la tierra, México, Fondo de Cultura Económica.

FIsHer, Lloyd (1951), "The Harverst Labour Market in California», The Quarterly Journal of Economics, vol. 65, núm. 4, pp. 463-491.

ForT, Odile (1979), La colonización ejidal en Quintana Roo, México, Instituto Nacional Indigenista.

García, Martha (2013), «Encuesta zafra 2011-2012. Jornaleros agrícolas de México y Centroamérica en los ingenios del sur-sureste: Retos para la política pública», Informe final, Chetumal, Ecosur-Sedesol-Conacyt.

Informe Jornaleros Safe (2012), Jornaleros mexicanos en EU con visa: los modernos olvidados, México, Centro Independiente de Trabajadores Agrícolas, United Farm Workes, Global Workers Justice Alliance, Dimensión Pastoral de la Movilidad Humana, Catholic Relife Service.

Instituto Nacional de Migración (INM) (2012), Programa de Migración para la Frontera Sur de México, en http://www.inm.gob.mx/index.php/page/Frontera_Sur (consultado el 10 de enero de 2013).

IzCARA, Simón (2010), Los jornaleros tamaulipecos y el Programa H-2A de trabajadores huéspedes, México, Universidad Autónoma de Tamaulipas-Plaza y Valdés Editores. (2012), «El aislamiento social de los trabajadores con visa H-2A. El ejemplo de los jornaleros tamaulipecos», Región y Sociedad, año xxIV, núm. 53, pp. 259-292.

LeVInE, Elaine (2004), «La otra cara de la migración: inserción laboral y estatus social de los migrantes mexicanos y latinos en Estados Unidos», en Elaine Levine (ed.),

\footnotetext{
$64 \frac{\text { SEGUNDO SEMESTRE } 2014}{\text { MIGRACIÓN Y DESARROLLO NÚM. } 23}$
} 
Inserción laboral de migrantes mexicanos y latinos en Estados Unidos, Cuadernos de América del Norte, México, CISAn-unam, pp. 87-104.

Mollard, Amédée (1977), Paysans exploités: essai sur la question paysanne, Grenoble, Presses Universitaires de Grenoble.

MORICE, Alain (1999), Recherches sur le paternalisme et le clientélisme contemporains: methods et interpretations, París, EHESS. (2001), "Choisis, contrôles, placés, Reouveau de l'utilitarisme migratoire», Vacarme, núm. 14, pp. 56-60.

NiETo, Rodrigo (2006), «Les conséquences géopolitiques pour le Mexique de la politique états-unienne de Homeland Security», Hérodote, núm. 123, pp. 164-180.

PaLACio, Roberto (2012), Albergue sustentable para jornaleros agrícolas en la región azucarera de Río Hondo, Quintana Roo (Propuesta para el ejido de Juan Sarabia), Chetumal, Instituto Tecnológico de Chetumal.

PAlidDA, Salvatore (1999), "La criminalisation des migrants», Actes de la Recherche en Sciences Sociales, núm. 129, pp. 39-49.

Pellerin, Héléne (1999), «Regionalisation of Migration Policies and Its Limits: Europe and North America Compared», Third World Quarterly, vol. 20, núm. 5, pp. 995-1011.

RuHs, Martin (2006), «Potentiel des programmes de migration temporaire dans l'organisation des migrations internationales», Revue Internationale $d u$ Travail, núm. 145, pp. 7-41.

Sagarpa (2007), Programa Nacional de la Agroindustria de la Caña de Azúcar, 2007-2012, México, Sagarpa.

Schiff, Maurice (2004), When Migrants Overstay their Legal Welcome: a Proposed Solution to Guest-Worker Program, IzA Discussion Paper, 1401, Bonn, IZA.

Trigueros, Paz (2008), «Los programas de los trabajadores huéspedes: las visas H-2A en Estados Unidos», Papeles de Población, núm. 55, pp. 117-144.

Winters, Alan, Terrie Walmsley, Zhen Kun Wang y Roman Grynberg (2003), «Liberalising the Temporary Movement of Natural Persons: an Agenda for the Development Round», World Economy, vol. 26, núm. 8, pp. 1137-1161. 
